\title{
Histórico da participação do Estado e da sociedade civil na formulação da Política Estadual de Segurança Alimentar e Nutricional no Ceará'
}

\section{History of the participation of the State and civil society in the formulation of the State Policy of Food and Nutrition Security in Ceará, Brazil}

\author{
Márcia Andréia Barros Moura Féa \\ (D) https://orcid.org/0000-0002-7886-3709 \\ E-mail: marcia.andreiaळuece.br \\ Lucia Conde de Oliveirab \\ (D) https://orcid.org/0000-0001-8265-7476 \\ E-mail: conde.luciaळgmail.com

\section{Maria Marlene Marques Ávila ${ }^{\mathrm{b}}$} \\ (D) https://orcid.org/0000-0002-8511-2524 \\ E-mail: marlene.avilaœuece.br \\ anniversidade Estadual do Ceará. Centro de Ciências da Saúde. \\ Fortaleza, CE, Brasil. \\ bUniversidade Estadual do Ceará. Centro de Estudos Sociais \\ Aplicados. Fortaleza, CE, Brasil.
}

\section{Correspondência}

Márcia Andréia Barros Moura Fé

Rua Doutor Silas Munguba, 1700. Itaperi. Fortaleza, CE, Brasil. CEP 60740-000.

\section{Resumo}

Este estudo visa descrever a participação da sociedade civil e do Estado na construção da Política Estadual de Segurança Alimentar e Nutricional no estado do Ceará, conhecendo o passado para compreender o presente e as perspectivas futuras. Para tanto, foi realizado levantamento bibliográfico sobre a seca e a fome no Ceará em livros, artigos e jornais, além disso, foram realizadas entrevistas semiestruturadas junto aos conselheiros do Conselho de Segurança Alimentar e Nutricional e militantes pelo direito humano a alimentação. As ações de combate à fome no Ceará tiveram início com a criação dos campos de concentração durante as secas, fato desconhecido pela maioria dos cearenses. A trajetória da formulação da política estadual de segurança alimentar foi entremeada com os movimentos de luta e o fortalecimento da participação social, que levou à conquista dos marcos legais do direito humano à alimentação no Ceará. No entanto, alguns desafios precisam ser enfrentados para a para a continuidade dessa política: investir na qualidade da participação social, no fortalecimento dos espaços de participação, conquistar apoio político, lutar pela garantia de financiamento, dar visibilidade à legislação e mecanismos de exigibilidade.

Palavras-chave: Participação Social; Segurança Alimentar e Nutricional; Política Pública.

1 Este artigo é resultado da tese de doutorado intitulada "Conselho de Segurança Alimentar e Nutricional Ceará e a formulação da Política Estadual de Segurança Alimentar e Nutricional” desenvolvida pela primeira autora no Programa de Pós-Graduação em Saúde Coletiva da Universidade Estadual do Ceará. 
Before the need of knowing the past to understand the present and plan for the future, we elaborated a memory to explain the participation of civil society and the State in the formulation of the State Policy on Food and Nutrition Security in Ceará. This paper presents the results of a bibliographic survey conducted in books, articles, and newspapers addressing the theme of drought and famine in Ceará, as well as of a semi-structured interview with the Councilors of the Food and Nutrition Security Council and members of the Human Right to Food. The (re)told story begins by recovering facts that are still unknown to most of Ceará's inhabitants, such as concentration camps during droughts, the formulation of the state policy on food security interspersed with social movements, strengthening of social participation, and the conquest of the right to food as a human right in Brazil and in Ceará. Despite these advancements, the continuity of this history still has to overcome some challenges, such as investing in the quality of social participation, strengthening participation spaces, gaining political support, guaranteeing financing, giving visibility to legislation, and enforcing mechanisms that ensure the human right to adequate food. Keywords: Social Participation; Food and Nutrition Security; Public Policy.
A participação da sociedade civil nas propostas de políticas públicas em geral teve início mundialmente na década de 1940, visando reforçar os mecanismos de democracia, abalados pelas guerras mundiais, $\mathrm{e}$ ampliar as responsabilidades do Estado em relação aos cidadãos (Testa, 1992). Apesar disso, no Brasil, a participação popular foi pouco expressiva nas políticas de alimentação e nutrição no entre 1940 e 1980 (Peliano, 2010).

No cenário brasileiro, a história das políticas de alimentação e nutrição se inicia na década de 1940 e ganha mais visibilidade em 1970 com a aprovação do II Programa Nacional de Alimentação e Nutrição (PRONAN), cuja ênfase foi dada às ações voltadas para o combate à desnutrição por meio de suplementação alimentar e distribuição de alimentos. Essas ações de cunho totalmente assistencialista tinham pouca associação com qualquer outra intervenção na área da saúde. Sintomaticamente, a nova Constituição em 1988 não incorporou o direito à alimentação entre os direitos sociais do cidadão brasileiro (Peliano, 2010).

Participação e debate sobre a fome e desnutrição foram se estruturando na década de 1980, mas somente a partir de 1990 a sociedade civil passou efetivamente a questionar as ações governamentais pontuais e assistencialistas presentes nessas políticas. A participação e controle social na década de 1990 foram fundamentais para a integração de diversas políticas públicas, descentralização da execução dos programas, mobilização e criação de marcos legais. Entre 1998 e 2010, houve claros avanços acerca da temática: em 2006, foi instituída a Lei Orgânica de Segurança Alimentar e Nutricional (LOSAN); em 2010, foi implementada a Política Nacional de Segurança Alimentar e Nutricional (PNSAN); e, finalmente, a inclusão do direito à alimentação na Constituição Federal, marco institucional no campo das políticas de alimentação e nutrição, resultado de intensa organização e participação da sociedade civil (Peliano, 2010).

Historicamente, a segurança alimentar foi introduzida na agenda política nacional nos anos $195^{\circ}$ por meio do trabalho pioneiro do médico e sociólogo Josué de Castro, ressaltando a fome 
como questão social (Castro, 2005); contudo, apenas retornariam ao cenário nacional sob a dimensão social nos anos 1990, com a Campanha da Ação da Cidadania Contra a Fome e a Miséria e pela Vida, coordenada pelo sociólogo Herbert de Souza, o "Betinho". A partir de 2003, após mais de 40 anos de políticas de alimentação e nutrição descontínuas, a segurança alimentar e nutricional foi tratada de forma clara, com propostas ajustadas à complexidade do tema e ações integradas para dar conta das múltiplas causas, sendo instituída como política pública em 2010, depois de anos de apoio e luta da sociedade civil organizada em torno desse tema (Instituto Cidadania, 2001).

O Estado brasileiro, ao aprovar a LOSAN, define a segurança alimentar e nutricional como:

[a] realização do direito de todos ao acesso regular e permanente a alimentos de qualidade, em quantidade suficiente, sem comprometer o acesso a outras necessidades essenciais, tendo como base práticas alimentares promotoras de saúde que respeitem a diversidade cultural e que sejam ambiental, cultural, econômica e socialmente sustentáveis. (Brasil, 2006)

Além disso, é instituído o Sistema Nacional de Segurança Alimentar e Nutricional - SISAN. Em 2010, ao publicar a PNSAN visando garantir a alimentação adequada como direito de todos, o governo assumiu, por meio de uma política de Estado, a desafiadora obrigação de prover, promover, proteger, fiscalizar e monitorar a segurança alimentar e nutricional e de instituir mecanismos de participação e controle da sociedade civil na exigência desse direito (Burlandy; Magalhães; Frozi, 2013).

O direito de estar livre da fome e a ter uma alimentação adequada constituem as dimensões do direito humano à alimentação adequada (DHAA). A expressão "direito humano à alimentação adequada” é definida pela ONU (1966) como um:

direito humano inerente a todas as pessoas de ter acesso regular, permanente e irrestrito, quer diretamente ou por meio de aquisições financeiras, a alimentos seguros e saudáveis, em quantidade e qualidade adequadas e suficientes, correspondentes às tradições culturais do seu povo e que garanta uma vida livre do medo, digna e plena nas dimensões física e mental, individual e coletiva.

Esse direito não deve ser garantido por meio de ações de caridade ou piedade, mas como uma obrigação do Estado mediado por condensação das relações de forças presentes numa dada sociedade (Gramsci, 1999). As políticas públicas devem ser planejadas visando corresponder às demandas da sociedade e se efetivam em diversos setores desta. São consideradas ações do Estado de interesse coletivo e não devem partir de decisões autoritárias do governo, devendo se configurar um processo de reciprocidade e antagonismo na relação entre Estado e sociedade civil (Parada, 2006).

A construção da PNSAN foi uma conquista da organização e mobilização de movimentos sociais, organizações não governamentais, gestores públicos, pesquisadores e outros atores sociais em torno da condição alimentar e nutricional dos indivíduos, família e comunidade. Alguns destes movimentos, conforme Maluf (2011), se iniciam na primeira metade do século XX, conquista que dialoga com a compreensão de participação social na perspectiva de Demo (2009), que a considera um princípio fundamental das políticas públicas, sendo uma conquista processual e inacabada, exigindo compromisso e envolvimento dos sujeitos sociais nas ações. No entanto, existe a necessidade de mudanças no comportamento da população em relação à reivindicação de diretos sociais, transformando o conformismo em participação organizada e atuante. Participação é conquista, portanto, em constante transformação, sempre fazendo e se refazendo. Demo (2009) reflete que a participação que se imagina completa nisso mesmo começa a regredir.

As políticas sociais estão enfrentando mais um período em que a política econômica, voltada para os interesses do capital, é priorizada e o atendimento aos direitos sociais são negligenciados. A radicalização do modelo neoliberal, com a aprovação da Emenda Constitucional $n^{\circ}$ 95/2016, resultou em menos recursos para atender a população, gerando redução da renda e de oferta de emprego e aumento das desigualdades sociais. Esta conjuntura atinge diretamente a SAN, principalmente pela diminuição 
do investimento nos programas que financiam a agricultura familiar, aumento da liberação de agrotóxicos e recuo nas políticas de preservação do meio ambiente.

No Ceará, a história da participação popular, compreendida como a intervenção da população mais desfavorecida nos processos de tensionamento para a busca de políticas sociais que respondam às suas demandas, se dá mais visivelmente em Fortaleza nos anos 1970 e se intensifica na década de 1980 , com a chamada "administração popular" do Partido dos Trabalhadores no governo municipal (Pereira; Ribeiro, 2009). Contudo, no final da década de 1980, a opção política de desenvolvimento no estado, marcada por uma administração neoliberal, fortalecedora do capital, focada na indústria e turismo, acentuou a concentração de renda e aumentou o desemprego tanto na zona rural como na cidade. Tal modelo não contribuiu para alterar o quadro social de pobreza e fome persistentes (Sampaio, 2002). Mesmo diante dessa realidade, a organização e mobilização da sociedade civil foi decisiva para a inclusão da segurança alimentar e nutricional na agenda de governo nesse estado.

A partir da década de 1990, o Ceará acompanhou o movimento nacional nos processos de formulação e implementação de estratégias e políticas de segurança alimentar e nutricional. Houve marcante mobilização da sociedade civil em torno da implementação da política estadual de segurança alimentar e nutricional, apesar do pouco apoio político evidenciado, com maior participação de organizações não governamentais e universidades.

Neste contexto, buscamos descrever o protagonismo da participação da sociedade civil na luta pelo direito humano à alimentação no Ceará, desvelando as lutas empreendidas, as lições aprendidas e refletindo sobre as possibilidades deste caminhar na busca de manter as conquistas e avançar no asseguramento deste direito. $O$ histórico descrito permite conhecer como se deu a luta da sociedade civil na construção da Política Estadual de Segurança Alimentar e Nutricional no Ceará (PESAN Ceará) e sua relação com o Estado, refletindo sobre a necessidade de união, articulações e discussão de resistência para a permanência e continuidade das ações de segurança alimentar e nutricional (SAN).

\section{Percurso Metodológico}

Este artigo é um recorte da tese intitulada "Conselho de Segurança Alimentar e Nutricional Ceará e a formulação da Política Estadual de Segurança Alimentar e Nutricional" que analisou a participação do Conselho Estadual de Segurança Alimentar e Nutricional Ceará na formulação da Política Estadual de Segurança Alimentar e Nutricional no Ceará.

Conforme Baptista e Mattos (2015), é importante que a análise de políticas conheça o contexto em que elas foram formuladas, como forma de compreender os sujeitos que fazem parte da sua história. Para sua realização, o estudo teve como cenário o Conselho Estadual de Segurança Alimentar e Nutricional no Ceará (CONSEA Ceará).

A produção de dados foi realizada no período de agosto a outubro de 2017 , a partir de entrevistas semiestruturadas com representantes do poder público e sociedade civil atuantes no CONSEA-CE. As entrevistas tiveram como pergunta central: na sua percepção, quais as contribuições da sociedade civil do estado e do CONSEA-CE em prol da luta pela segurança alimentar e nutricional e garantia do direito humano a alimentação adequada no Ceará? Além disso, foi realizado levantamento bibliográfico sobre a seca e a fome no Ceará por meio de busca em livros, artigos e jornais.

Constituíram-se como sujeitos 14 conselheiros(as), dez dos quais são representantes da sociedade civil (denominados SC, $\mathrm{SC} 1, \ldots$..), e quatro do poder público (PP, $\mathrm{PP} 1, .$.$) . Entre os que representavam a sociedade$ civil, foram entrevistados oito conselheiros atuantes no CONSEA-CE e dois ex-conselheiros, sendo um deles a presidente do CONSEA-CE e o outro um exatuante da primeira gestão deste conselho. Os exconselheiros foram incluídos pelo seu papel na construção da história da SAN no Ceará, não só no espaço do conselho, mas pela sua militância na luta política em prol do DHAA tanto na esfera estadual, quanto na federal e municipal.

A maioria destes sujeitos era do sexo feminino (10), representando a sociedade civil no CONSEA-CE, desde 2003, ano de sua criação. Essas mulheres tinham ensino superior completo nas áreas de alimentação, nutrição, biblioteconomia, sociologia 
e serviço social. Além disso, suas rendas familiares variam entre 4 e 20 salários-mínimos e representavam no conselho os segmentos ligados à indústria, comércio e agricultura; redes e fóruns; associação e movimentos sociais; ensino e pesquisa; povos e comunidades tradicionais (somente povos de terreiro afrodescendente e pesca); gênero e gerações; produção agroecológica e orgânica e de direitos humanos e sociais. A maior parte dos sujeitos participava de outros conselhos de forma concomitante $(64,0 \%)$, e as instituições representadas realizavam ações voltadas para a garantia da segurança alimentar e nutricional (SAN).

A análise foi realizada pela técnica da análise temática, conforme Minayo (2008), e norteada pela categoria participação social, conforme Demo (2009). Os resultados estão apresentados de forma que os dados bibliográficos são complementados com os dados das entrevistas.

O estudo foi aprovado pelo Comitê de Ética em Pesquisa com Seres Humanos da Universidade Estadual do Ceará sob parecer n 1.691.577/2016.

\section{Resultados e discussões}

No levantamento bibliográfico, as buscas revelaram períodos críticos de seca no Ceará entre os anos 1877/1879; 1914/1915; 1932; 19791984, ao longo dos quais a criação de campos de concentração, nos anos de 1915 e 1932, foi um fato marcante e triste de ações governamentais instituídas para "combater a fome", com pouca ou nenhuma participação da sociedade civil. Nos anos de 1993, 1998, 2001 e 2015, novamente a seca voltou a se repetir e, apesar de pressões e demandas da sociedade civil organizada, visando a garantia de água e alimentação à população, não foram observadas ações estruturantes do poder público capazes de minimizar o sofrimento do sertanejo nesses períodos.

\section{Campos de concentração no Ceará: a face cruel da exclusão social}

Nos séculos XIX e XX, a população do Ceará experimentou vários períodos de seca marcados, por um lado, pela busca de sobrevivência e, por outro, pelo êxodo rumo à capital, Fortaleza, e para outros estados. A omissão do governo cearense no combate à seca e a fome foi evidente ao longo desse período, pois os dirigentes acreditavam que a seca era provocada por causas naturais. 0 pensamento da população atrelava à seca a vontade divina, e o governo se dizia influenciado por esse fato (Lacerda, 2006).

Em pleno desenvolvimento do capitalismo, no apogeu do algodão, explode a primeira seca registrada no Ceará, em 1877, revelando grandes problemas sociais. Fortaleza foi ocupada por muitos sertanejos fugindo da fome no interior do Ceará, as ruas ficaram cheias de pedintes e doentes, e essas pessoas viviam em um mesmo local, afastado da capital, facilitando a disseminação de doenças e provocando muitas mortes (Carapinima, 2015). A grave situação de miséria da população pobre foi descrita nos livros de Rodolfo Teófilo, impactado com as cenas vivenciadas na seca, denunciando a negligência do governo e a cumplicidade da burguesia nessa tragédia (O Legado, 2016).

A queda do preço do algodão fez a economia cearense entrar em crise. A conjunção do declínio financeiro com a seca de 1877 a 1879 provocou grandes transformações sociais e econômicas, tais como: descapitalização, migração da população do sertão para Fortaleza e as tentativas do governo e das classes de maior poder aquisitivo de controlar o êxodo rural. As ações de governo eram demoradas e pontuais, e as chuvas só ocorreram em abril de 1880. O momento era de busca de recuperação econômica local e o discurso dos governantes mudou, sendo direcionado para a necessidade de trabalho e educação como regeneradores da situação de miséria que os sertanejos se encontravam. Contudo, a forma assistencialista e excludente como foi tratada essa situação evidenciou mais ações violentas em busca de ordem social e disciplina e a fome ganhou uma dimensão política importante (Brito, 2013).

Seguindo-se a esta grande seca, veio a de 1915. Benjamin Liberato Barroso, então governador, apresentou como solução para conter os milhares de sertanejos que chegavam novamente de todas as regiões em busca de melhores condições de vida, a criação de um campo de concentração na localidade conhecida como Alagadiço, área 
periférica de Fortaleza, para abrigá-las. Durante o período de existência desse campo (o ano de 1915), foram registradas 150 mortes por dia devido à falta de higiene e alimentação. As notícias nos jornais assumiam um tom de reivindicação de ações governamentais na problemática da seca e fome no Ceará, alertando que a falta de pão e dinheiro era fruto da ganância de políticos e do desinteresse em apontar soluções, numa tentativa de sensibilizar que o sertanejo não continuaria resignado a sofrer, se tivesse consciência e orientação para agir (Lacerda, 2006).

Em 1932, outra estiagem de chuva foi evidenciada e, dezessete anos depois, o governador do Ceará, Roberto Carneiro de Mendonça, com o apoio de Getúlio Vargas, então presidente, ampliou a experiência anterior criando campos de concentração em Fortaleza, nos bairros Otávio Bonfim e Moura Brasil e em cidades estratégicas do interior cearense, como Ipu, Quixeramobim, Senador Pompeu, Cariús e Crato. A criação destes campos era parte das políticas de obras contra a seca instituídas, que visavam oferecer alimentação e assistência à saúde. A estrutura e localização dos campos eram similares entre si, contando com posto médico, cozinha, barbearia, capela e casebres separados por família. Em Fortaleza, ficavam situados próximos à linha férrea, facilitando o acesso do povo que chegava de trem a esses locais e impedindo que entrassem para outros bairros da cidade (Rios, 2014; Nóbrega, 2017).

Em junho de 1932, o número de pessoas nesses locais somava 73.918, sendo mais numerosos em Senador Pompeu, ${ }^{2}$ Crato e Cariús. Os campos de concentração foram batizados como "currais do governo”, pois as pessoas eram vigiadas para não fugir, e funcionaram de março de 1932 a abril de 1933; sendo extintos quando as chuvas chegaram. Os campos de fato serviram para concentrar milhares de sertanejos famintos, encurralados e afastados da sociedade e para controlar a migração para a cidade de Fortaleza. Com o confinamento, muitas mortes aconteceram devido à exposição às doenças e à fome, e não necessariamente pela seca (Brito, 2013; Rios, 2014; Nóbrega, 2017). A memória da criação de campos de concentração para combater a fome no Ceará foi relatada por um dos sujeitos entrevistados, revelando que esse fato é desconhecido pela maioria da população cearense e até mesmo por parte dos que lutam pela SAN no estado.

A seca não é um problema exclusivamente climático, mas também de negligência do poder público, que executa projetos ineficientes para solucionar essa problemática e não reconhece a concentração de renda e as desigualdades sociais como responsáveis pela situação (Brito, 2013; Carapinima, 2015). Na verdade, a ação do governo retratava que ter ou não ter o que comer dividia mais que etnia; dividia a sociedade não em burguesia e proletariado, mas entre os que não comem e não dormem porque têm fome e os que comem, mas não dormem com medo dos que têm fome (Castro, 2005). O livro $O$ Quinze, da escritora Raquel de Queiroz, retrata o descaso governamental ao lidar com a população sertaneja, a importância e magnitude da seca no sertão do Ceará, evidenciando o caráter autoritário e excludente das ações de governo e a ausência de vontade política para o controle da situação de seca e fome (Queiroz, 1982).

Outras secas atingiriam o Nordeste nas décadas seguintes. A mais abrangente delas teve início em 1979 e durou quase cinco anos. Fome e saques se espalharam pela região, morreram 3,5 milhões de pessoas por conta de enfermidades relacionadas à desnutrição, demonstrando, mais uma vez, que, sem uma política estruturante de combate às desigualdades sociais com geração de renda, a criação de açudes isoladamente ou qualquer outra solução para reservar água não teria êxito para resolver a problemática (Lacerda, 2006).

As ações governamentais estabelecidas em anos de grandes secas no Ceará, voltadas para o combate à fome e seca, foram assistencialistas, pontuais, excludentes, caracterizadas pela pouca participação e envolvimento da sociedade civil, sem ações estruturantes que pudessem também intervir conforme a necessidade e realidade das famílias cearenses. Novamente a seca assolou o Ceará nos anos de 1993 a 1998, 2001 e 2015. Mais de 100 anos

2 Em 2019, o campo de concentração, localizado em Senador Pompeu, no interior do Ceará, foi tombado como patrimônio histórico. 
depois da sua pior seca, a de 1915, o povo cearense continua sofrendo nos períodos de estiagem. Os campos de concentração foram substituídos pela proliferação das comunidades marginalizadas, vivendo em condições insalubres, sem nenhum saneamento básico, sem empregos. A exclusão social revela sua face mais cruel, com o total desrespeito aos direitos essenciais do ser humano, entre eles, o mais básico: o direito à alimentação. Neste cenário, as primeiras mobilizações da sociedade civil no referido estado ocorreram a partir da década de 1970, iniciando um período de lutas pela conquista deste direito.

\section{Sociedade civil e Estado nas trilhas do caminho para a formulação da Política de Segurança Alimentar e Nutricional no Ceará}

Na década de 1970, as primeiras ações da sociedade civil no Ceará para o combate a fome no estado foram motivadas pela dificuldade de conseguir sementes para o plantio e subsistência do sertanejo, sendo uma resposta ao desamparo da população pobre na seca. Dessa forma, a Diocese de Crateús criou um Banco de Sementes, mais tarde denominado "Casas de Sementes Crioulas", que visava estocagem e multiplicação de sementes importantes para atender às necessidades locais, resgatando e preservando espécies tradicionalmente cultivadas na região e já adaptadas às condições locais. 0 surgimento dos bancos de sementes se deu a partir das necessidades dos agricultores, que, para conseguir sementes, tinham que trabalhar de graça ou fazer empréstimos a juros. Esta ação foi importante para promover autonomia, diminuindo a dependência em relação aos proprietários de terra, se constituindo em espaço de luta para questionar a exploração, a pobreza e fortalecer a mobilização social. Os bancos de sementes aliviaram a situação de fome de muitos sertanejos (Esplar, 2017).

A comunidade foi incentivada a guardar sementes e, quando surgia a necessidade, qualquer pessoa da família associada podia pegá-las e utilizá-las para plantio, sem custo, devolvendo novas sementes. Caso a falta de chuvas impedisse a família de devolver as sementes que pegou emprestadas, ela podia esperar por mais um ano e somar um pequeno acréscimo de sementes na hora da devolução.

Entre os anos de 1970 e 1980, as ações de governo para o combate a fome no Ceará continuavam sendo pontuais, centralizadas praticamente em uma secretaria, sendo a alimentação apenas um componente a mais nos programas sociais, sem a visão da complexidade que envolve esta questão.

Em 1993, em plena efervescência da Campanha da Ação da Cidadania Contra a Fome e a Miséria e pela Vida, liderada por Herbert de Souza, campanha essa que criou comitês de combate a fome em todo o Brasil (Arruda; Arruda, 2007; Costa; Pasqual, 2006), o Ceará envolveu a sociedade civil e órgãos públicos em torno dos referidos comitês. A participação da sociedade civil foi intensa, tendo como protagonistas professores da Universidade Federal do Ceará aliados a membros de associações dos funcionários de bancos (Banco do Nordeste, Banco do Brasil, Banco Estadual do Ceará, Caixa Econômica), do Serviço Social do Comércio SESC, de movimentos sindicais (Central Única dos Trabalhadores CUT), das organizações não governamentais (Comitê de Entidades no Combate à Fome e Pela Vida/Rede Nacional de Mobilização Social - COEP/CE, Centro de Pesquisa e Assessoria ESPLAR, Centro de Estudos do Trabalho e Assessoria ao Trabalhador CETRA, Articulação do Semiárido Brasileiro ASA, Caritas Brasileira, Pastoral da Criança), dos movimentos sociais (Movimento Sem Terra MST); e também de empresas públicas (Instituto Nacional de Colonização e Reforma Agrária INCRA, Empresa Brasileira de Pesquisa Agropecuária EMBRAPA), conforme relato a seguir:

[...] os movimentos sociais, as ONGs, universidades, eu vejo como fundamentais neste processo de caminhada de construção de segurança alimentare nutricional no Ceará, a sociedade civil, teve um papel muito forte, a gente que levantava as discussões, criava as pautas, criava os eventos, organizava, as vezes tínhamos ajuda do poder público, mas a sociedade civil sempre que puxava. (SC2, 2017)

Essa organização da sociedade civil era motivada pela necessidade de politizar a questão da fome, o grupo muito engajado, levantava discussões 
por meio de entrevistas em programas de rádio, palestras, reuniões, seminários alertando que a fome não era um fenômeno natural, sendo influenciada por questões sociais e econômicas, o que contribuiu para a criação de um conselho de segurança alimentar estadual, que foi extinto em 1994. A força de organização da sociedade civil no Ceará, principalmente por meio do Ação da Cidadania, mobilizou 122 delegados(as), representando a sociedade civil e o poder público, a participar da I Conferência Nacional de Segurança Alimentar, ocorrida em Brasília, em julho de 1994, sendo a segunda maior delegação presente. Antecedendo a conferência nacional, o Ceará realizou em Fortaleza a I Conferência de Segurança Alimentar, precedida por conferências regionais no Cariri, no Sertão Central, Centro-Sul e Crateús para discutir sobre as causas da fome.

O tema da primeira conferência foi "Fome, Questão Nacional”, cujo relatório final exprimia a preocupação com a concentração de renda e de terra, vista como um dos principais determinantes da fome e miséria no país. Houve forte mobilização dos estados, principalmente pelos comitês da Ação da Cidadania e de movimentos sociais de nível nacional, como a Central Única dos Trabalhadores (CUT), Confederação dos Trabalhadores na Agricultura (CONTAG) entre outras, acompanhadas de suas representações estaduais. Afora a mobilização obtida, a conferência deixou como legado um conjunto de resoluções para direcionar os próximos passos do movimento pela segurança alimentar no país. Por conta da redefinição da orientação da política social devido à mudança da gestão nacional, a qual não reconheceu mais o combate à fome como uma prioridade, o legado dessa conferência, de grande importância na história da política de SAN, não foi efetivado (Menezes, 2010). Além desta, o Ceará realizou quatro conferências estaduais nos anos de 2004, 2007, 2011 e 2015, as quais antecederam as conferências nacionais de Segurança Alimentar e Nutricional.

Entre 1995 e 1996, as ações do grupo da sociedade civil envolvido com a Ação da Cidadania no Ceará contribuiu para que o Programa Mundial de Alimentos (PMA) da Organização das Nações Unidas, escolhe-se esse estado para fazer um piloto de um projeto voltado para a municipalização da merenda escolar. O município cearense de Canindé foi escolhido porque tinha mais assentamentos rurais, sendo constatado que, se a compra de alimentos para a merenda escolar fosse feita nos assentamentos direto do agricultor familiar, as necessidades de alimentos para as escolas seriam completamente saciadas. Esses resultados foram utilizados como subsídios para a utilização da agricultura familiar na merenda escolar no Brasil muitos anos depois.

No contexto nacional, com a posse do presidente Luiz Inácio Lula da Silva, em 2003, a SAN volta a ser priorizada o que se concretiza por meio da implantação do Programa Fome Zero. Nesse governo, o maior interesse político de abertura para participação social reativou o CONSEA Nacional, impulsionando a organização de muitos conselhos estaduais e municipais, visando elaborar diretrizes para a política local e articular a participação da sociedade civil.

Nesse período, o Conselho Estadual de Segurança Alimentar e Nutricional - Ceará (CONSEA-CE) foi (re)criado pelo Decreto n ${ }^{0}$ 27.008/2003, sendo um órgão de assessoramento do Governo do Estado do Ceará, integrando o Sistema Nacional de Segurança Alimentar e Nutricional (SISAN), vinculado à STDS.

Na primeira eleição para presidência do CONSEACE, houve marcante disputa entre representantes do poder público e sociedade civil, sendo eleito um representante da sociedade civil, o que foi decisivo para iniciar a construção de uma trajetória de SAN no Ceará baseada em um processo de partilha de poder entre a sociedade civil e o poder público:

[...] desafio foi a relação governo e sociedade civil, pelo fato do CONSEA ser majoritariamente sociedade civil, isso incomodava demais, por que eles achavam que o conselho não poderia ser assim ... a maior parte dos conselhos continua ainda sendo a maioria do governo, ou então meio a meio; então isso não é apenas uma questão de quantidade, é uma questão de relação de poder, acho que se inaugura uma discussão onde a gente abre o espaço para a discussão sobre a partilha do poder e que a sociedade civil tem muito a contribuir para que aconteça esse avanço nas questões da política de soberania e SAN. $(\mathrm{SC} 8,2017)$ 
Aliado ao interesse de participação da sociedade civil, este conselho nasceu forte, organizado e sempre teve como diferencial reuniões mensais. 0 desafio era a forma de definição dos membros da sociedade civil, que incialmente foram designados pelo governador do estado, segundo o mesmo procedimento utilizado para a escolha dos representantes do poder público. A composição do CONSEA Ceará é de $2 / 3$ de representantes da sociedade civil e $1 / 3$ do poder público (CEARÁ, 2003). Atualmente, existem 36 conselheiros titulares e 36 suplentes, a maioria membros da sociedade civil, incluindo a presidência.

Como estratégia para ampliar a participação da sociedade civil na discussão da SAN, foi criado, em 20 de março de 2003, o Fórum Cearense de Segurança Alimentar e Nutricional, atualmente denominado Fórum Cearense de Soberania e Segurança Alimentar e Nutricional (FCSSAN). Na percepção dos sujeitos, a criação do CONSEA-CE interferiu muito na ação do fórum, que perdeu parte se seu protagonismo.

Em 2004, o CONSEA-CE realizou, por meio de uma articulação política, uma audiência pública na Câmara dos Vereadores de Fortaleza no intuito de apresentar uma proposta de uma política de SAN para o município. Foi a primeira vez que se discutia essa temática na câmara. Nessa mesma época, uma deputada estadual solicitou a elaboração de uma proposta de lei para as cantinas escolares, ação que foi coordenada por uma conselheira da sociedade civil. A proposta foi elaborada, aprovada na assembleia, mas vetada pelo governador, o que, na percepção dos sujeitos, foi determinado por interesses pessoais e de mercado.

Um momento relevante da trajetória de SAN no Ceará foi a formação de atores sociais, entre os anos de 2004 e 2006, pelo Projeto de Capacitação de Atores Sociais em Segurança Alimentar e Nutricional (CapacitaSAN) realizado pelo CONSEA Ceará, Fórum Cearense de SAN e Rede de Educação Cidadã Talher Ceará, com financiamento do Ministério de Desenvolvimento Social. A capacitação foi realizada em 61 municípios com o objetivo de estimular o desenvolvimento de consciência crítica para a formulação de políticas públicas participativas de SAN no Ceará (Braga; Azevedo; Miranda, 2008).

Em 2007, a realização da III Conferência de Nacional SAN, em Fortaleza, teve como tema central "Por um Desenvolvimento Sustentável com Soberania e SAN" e apontou como prioridades a necessidade de implementação da Política Nacional de SAN; elaboração e monitoramento do Plano Nacional de Segurança Alimentar e Nutricional e criação do Fundo Nacional de Segurança Alimentar e Nutricional (Brasil, 2008).

Outra ação importante na área de SAN foi a avaliação do Programa da Alimentação Escolar (PNAE) em Santana de Acaraú-CE, entre os anos de 2008-2009, pois a gestão municipal vinha inovando ao adquirir alimentos diretamente de produtores da agricultura familiar, reduzindo a compra de alimentos oriundos de indústrias ou grandes atacadistas de outros estados. Esta experiência antecipou-se à obrigatoriedade da Lei $\mathrm{n}^{0} 11.947 / 2009$, que regulamentou a obrigatoriedade de compra da agricultura familiar de no mínimo 30\% dos alimentos utilizados no PNAE, priorizando-se os assentamentos da reforma agrária, as comunidades tradicionais indígenas e comunidades quilombolas.

Os marcos legais de SAN no Ceará foram instituídos nos anos de 2011 e 2012. Em 2011, foi aprovada a LOSAN estadual (Lei $n^{0} 15.002 / 2011$ ), que trata da criação do SISAN, das diretrizes para o Plano Estadual de SAN, e deram-se outras providências. Em 2012, foi regulamentada a Câmara Intersetorial de Segurança Alimentar e Nutricional (CAISAN-CE)

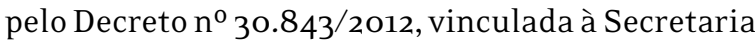
do Trabalho e Desenvolvimento Social (STDS). Atualmente, a CAISAN-CE se vincula à Secretaria de Proteção Social, Justiça, Cidadania, Mulheres e Direitos Humanos, através da Célula de Segurança Alimentar e Nutricional (CSAN). Com a instalação da célula de SAN na STDS, houve ampliação das atividades concernentes à política estadual de SAN .

Ainda em 2012, o Ceará elaborou o primeiro Plano de Segurança Alimentar e Nutricional (PLANSAN), com vigência para os anos de 2012-2015, sendo um dos primeiros estados a realizar essa ação. 0 segundo PLANSAN Ceará, se refere ao período de 2016-2019. Desde a implantação dos marcos legais, a adesão ao SISAN pelos municípios cearenses, aconteceu em 41 municípios de um total de 184.

Entre as conquistas para a participação social no CONSEA-CE, pode-se citar a escolha dos representantes da sociedade civil, que passou a ser realizada por meio 
de edital a partir de 2014, bem como a inclusão dos povos e comunidades tradicionais, de acordo com as diretrizes da Conferência Estadual de Segurança Alimentar e Nutricional.

Além do citado, outra importante conquista para a participação social no CONSEA-CE foi a instituição da Política de Aquisição de Alimentos da Agricultura Familiar do Estado do Ceará (Lei $n^{0} 15.910 / 2015$ ), regulamentada pelo Decreto $\mathrm{n}^{0} 32.315 / 2017$. 0 decreto estabelece a realização da modalidade de compras institucionais por meio de chamada pública para o atendimento de demandas de consumo de alimentos e de procedimentos licitatórios para contratação de serviços de fornecimento de alimentação pelos órgãos e entidades da administração pública estadual. Determinou também que a aquisição de alimentos da agricultura familiar fosse integrada ao Sistema de Compras do Governo do Estado do Ceará, visando propiciar maior agilidade e transparência na aquisição de gêneros alimentícios para a administração pública estadual, bem como o fortalecimento da agricultura familiar. Apesar de todos esses avanços legais, o controle social para execução da política supracitada precisa ser fortalecido pelo CONSEA-CE.

O fortalecimento da segurança alimentar e nutricional no Ceará repercutiu no declínio da insegurança alimentar revelado pelas Pesquisas Nacionais por Amostra de Domicílios (PNAD, 2004, 2009, 2014) (Brasil, 2004; 2009; 2014). Contudo, os sujeitos têm clareza quanto aos desafios para a consolidação do DHAA, sendo importantes destaques entre estes o insuficiente conhecimento sobre este direito por parte da população, o baixo financiamento, o estabelecimento de mecanismos de exigibilidade do direito e a necessidade de incluir o DHAA na Constituição do Ceará.

Este estudo revelou o protagonismo da sociedade civil para a construção e fortalecimento das ações de SAN no Ceará, apesar do reduzido apoio político para a gestão de tais ações, o que demonstra a necessidade da vigilância da sociedade civil para manter as conquistas.

Tal afirmativa se reforça pela vulnerabilidade da participação social na política de SAN, que, no cenário nacional, foi duramente atingida pela extinção do CONSEA nacional pelo governo de Jair Bolsonaro.

\section{Considerações finais}

O estudo demonstrou a participação ativa da sociedade civil cearense na luta pelo DHAA. A formulação da política estadual de segurança alimentar e nutricional no Ceará passou por um importante processo de institucionalização, sendo decisiva a participação da sociedade civil na sua formulação. Observou-se um avanço na consolidação dessa política, a inclusão da segurança alimentar e nutricional na agenda de governo foi um passo importante da gestão pública nessa área. A participação e organização da sociedade civil, ao longo dos anos, foram decisivas para a segurança alimentar e nutricional ganhar espaço na cena pública estadual; para a criação do CONSEA-CE e para a construção dos marcos legais essenciais à garantia do direito à alimentação no Ceará.

Apesar das conquistas, há o reconhecimento que falta muito a fazer. Em última análise, este fato revela que à medida que a SAN se institucionaliza no Brasil, o Ceará busca vencer as relações de poder instituídas e a falta de interesse político Mesmo com o avanço na institucionalização da política de SAN no Ceará, a gestão pública permanece demonstrando falta de vontade política para superação da insegurança alimentar no estado, seguindo o modelo de desenvolvimento nacional de redução do investimento nas políticas sociais, o que fortalece a concentração de renda.

A organização da sociedade civil, no sentido de adquirir e ampliar sua capacidade social e política para interferir efetivamente na agenda de governo no Ceará, precisa investir na qualidade da participação, no fortalecimento dos espaços de participação, conquistar apoio político, lutar pela garantia de financiamento, dar visibilidade à legislação e mecanismos de exigibilidade, compreendendo a complexidade de mais este desafio, mas também, sua essencialidade para o avanço da realização do DHAA.

\section{Referências}

ARRUDA, B. K. G.; ARRUDA, I. K. G.. Marcos

referenciais da trajetória das políticas de alimentação e nutrição no Brasil. Revista Brasileira de Saúde Materno Infantil, Recife, 
v. 7, n. 3, p. 319-326, 2007. DOI: 10.159o/S151938292007000300011

BAPTISTA, T. W. F.; MATTOS, R. A. Sobre Política (ou o que achamos pertinente refletir para analisar políticas). In: MATTOS, R. A.; BAPTISTA, T. W. F. Caminhos para análise das políticas de saúde. Porto Alegre: Rede Unida, 2015.

BRASIL. Lei ${ }^{0}$ 11.346, de 15 de setembro de 2006. Cria o Sistema Nacional de Segurança Alimentar e Nutricional - SISAN com vistas em assegurar o direito humano à alimentação adequada e dá outras providências. Diário Oficial da União: Brasília, DF, 18 set. 2006.

BRASIL. Pesquisa Nacional por Amostra de Domicílios: segurança alimentar 2013. Rio de Janeiro: IBGE, 2014.

BRASIL. Assistência social e segurança alimentar e nutricional. Políticas Sociais: acompanhamento e análise, n. 16, p. 62-64, 2008.

BRAGA, E. F.; AZEVEDO, H. S.; MIRANDA, R. B. Caderno CapacitaSAN: uma experiência de formação de atores sociais em segurança alimentar e nutricional no Ceará. Fortaleza: Expressão Gráfica, 2008.

BRITO, L. A fome: retrato dos horrores das secas e migrações cearenses no final do século XIX. Estação Literária, Londrina, v. 1ob, p. 111-125, 2013. BURLANDY, L.; MAGALHAES, R.; FROZI, D. Políticas públicas de segurança alimentar e nutricional. In: ROCHA, C.; BURLANDY, L.; MAGALHÃES, R. Segurança alimentare nutricional: perspectivas, aprendizados e desafios para as políticas públicas. Rio de Janeiro: Editora Fiocruz, 2013, p. 89-107.

CARAPINIMA, J. Centenário da seca de 1915 no Ceará. Jornal Inverta, n. 478, 2015.

CASTRO, J. Geografia da fome. 5. ed. Rio de janeiro: Civilização Brasileira, 2005.

CEARÁ.. Perfil da Segurança Alimentar no Estado do Ceará. Fortaleza: Secretaria do Trabalho e Desenvolvimento Social; IPECE, 2011.

COSTA, C. A.; PASQUAL, M. Participação e políticas públicas na segurança alimentar e nutricional no Brasil. In: GARCÉS, M. et al. Democracia y ciudadanía en el Mercosur. Santiago: LOM, 2006. p. 319-328.

DEMO, P. Participação é conquista: noções de política social participativa. 6. ed. São Paulo: Cortez, 2009.

ESPLAR. Memórias do Esplar: o surgimento da rede de intercâmbio de sementes, 2017. Disponível em: <https://bit.ly/3wTLPR3>. Acesso em: 21 jan. 2018.

GRAMSCI, A. Cadernos do cárcere. Tradução:

Carlos Nelson Coutinho. Rio de Janeiro:

Civilização Brasileira, 1999. v. 1.

INSTITUTO CIDADANIA. Uma proposta de política de segurança alimentar para o Brasil. Brasília, DF: 2001.

LACERDA, F. G. Entre o sertão e a floresta: natureza, cultura e experiências sociais de migrantes cearenses. Revista Brasileira de História, São Paulo, v. 26, n. 51, p. 197-225, 2006. DOI: 10.1590/So102-01882006000100010

MALUF, R. S. J. Segurança alimentar e nutricional. Petrópolis: Vozes, 2011.

MINAYO, M. C. S. O desafio do conhecimento: pesquisa qualitativa em saúde. São Paulo: HUCITEC, 2008.

MENEZES, F. Mobilização social e participação da sociedade civil. In: ARANHA, A.V. Fome Zero: uma história brasileira. Brasília, DF: Ministério do Desenvolvimento Social e Combate à Fome, 2010. v. 1. p. 120-132.

NÓBREGA, J. Campos de concentração no Ceará. Diário do Nordeste, Fortaleza, 29 maio 2017. Disponível em: <https://bit.ly/3uBıhzW>. Acesso em: 20 jan. 2018.

ONU - ORGANIZAÇÃO DAS NAÇÕES UNIDAS. Pacto Internacional dos Direitos Econômicos, Sociais e Culturais. Nova York: ONU 1966.

PARADA, E L. Política y políticas públicas. In: SARAVIA, E.; FERRAREZI, E. Políticas públicas. Brasília, DF: Escola Nacional de Administração Pública, 2006, p. 43-95.

PELIANO, A. Lições da história: avanços e retrocessos na trajetória das políticas públicas 
de combate à fome e pobreza no Brasil. In:

ARANH, A. V. Fome Zero: uma história brasileira.

Brasília, DF: MDS; Assessoria Fome Zero, 2010.

p. 26-41. v. 1.

PEREIRA, E. M.; RIBEIRO, S. P. Participação popular nos marcos do capital: o projeto

Raízes de Cidadania em questão. Mediações, Londrina, v. 14, n. 1, p. 237-259, 2009.

DOI: 10.5433/2176-6665.20o9v14n1p237

QUEIROZ, R. O quinze. 28. ed. Rio de Janeiro: J. Olímpio, 1982.
RIOS, K S. Isolamento e poder: Fortaleza e os campos de concentração na Seca de 1932. Fortaleza: Imprensa Universitária, 2014.

SAMPAIO, J. L. F. Novas estratégias de combate à seca e à fome no Ceará: a construção de um poder. Mercator, Fortaleza, v. 1, n. 2, p. 27-39, 2002. DOI: $10.4215 /$ rm.v1i2.179

O LEGADO de luta da Rodolfo Teófilo. Jornal Inverta, Rio de Janeiro, n. 483, 2016.

TESTA, M. Pensar em saúde. Porto Alegre: Artes Médicas; Abrasco, 1992.

\section{Contribuição dos autores}

Todos os autores participaram da concepção, análise e interpretação dos dados; redação do artigo ou a sua revisão crítica; e aprovação da versão a ser publicada.

Recebido: 19/12/2019

Reapresentado: 01/10/2019; 19/12/2019

Aprovado: 29/04/2021 